\title{
Current Research in
}

\section{Bioorganic \& Organic Chemistry}

\section{Facile Synthesis of Excellent Anti-Corrosive Bi-Layer Structure Composite Coatings on Mg Alloys}

\author{
Sung-Nam Pak ${ }^{1,2 *}$, Kyong-Sik Ju ${ }^{3}$, Chang-Son Ok ${ }^{1}$, Kwang-Won Nam ${ }^{1}$, Chang-Su Pak ${ }^{3}$ \\ 'Department of Energy Science, Kim Il Sung University, Pyongyang 999093, Democratic People’s Republic of Korea \\ ${ }^{2}$ State Key Laboratory of Urban Water Resource and Environment, School of Chemistry and Chemical Engineering, Harbin Institute of \\ Technology, Harbin 150001, China \\ ${ }^{3}$ Institute of Advanced Science, Kim Il Sung University, Pyongyang 999093, Democratic People’s Republic of Korea
}

"Corresponding author: Sung-Nam Pak, Department of Energy Science, Kim Il Sung University, Pyongyang 999093, Democratic People's Republic of Korea. Tel: +15124580642; Email: 15124580642@163.com

Citation: Pak SN, Ju KS, Ok CS, Nam KW, Pak CS (2019) Facile Synthesis of Excellent Anti-Corrosive Bi-Layer Structure Composite Coatings On Mg Alloys. Curr Res Bioorg Org Chem 3: 121. DOI: 10.29011/2639-4685.100021

Received Date: 22 April, 2019; Accepted Date: 09 May, 2019; Published Date: 17 May, 2019

\begin{abstract}
The excellent anti-corrosive bi-layer structure composite coatings were fabricated on AZ31B Mg alloys. Magnesium substrates were first treated by Micro-Arc Oxidation (MAO) method in the silicate-based electrolyte containing silane as an organic additive and then modified by phytic acid and silane in sequence. The surface morphologies and composition of the as-fabricated composite coatings were characterized by SEM, EDX and XPS, and the corrosion resistance was evaluated by electrochemical tests in $3.5 \% \mathrm{NaCl}$ solution. The results showed that the composite coatings remarkably enhanced the corrosion resistance, compared with $\mathrm{Mg}$ alloy substrate due to the improved microstructure of MAO coating and the sealing effect for micro-defects.
\end{abstract}

Keywords: Bi-Layer Structure Composite Coatings; Corrosion Resistance; Magnesium; Micro-Arc Oxidation; Organic Additive

\section{Introduction}

As Mg alloys have low density, high specific strength, and good electromagnetic shielding, they are widely applied in many fields such as aerospace, automotive, electronics industries, biomedicine and so on. However, the poor corrosion resistance has restricted its application in the aggressive environment such as acidic environment or salt-water condition [1-4]. The MicroArc Oxidation (MAO) is widely applied to valve metals such as $\mathrm{Mg}, \mathrm{Al}, \mathrm{Ti}, \mathrm{Zr}$, Ta and its alloys as one of surface modification techniques capable of improving the anti-corrosive performance of $\mathrm{Mg}$ alloys. The MAO process is based on the anodization of valve metals in aqueous solutions at applied potential greater than breakdown voltage (typically from $400 \mathrm{~V}$ to $600 \mathrm{~V}$ ) of the original oxide film. The numerous micro discharges are continuously formed on the MAO coating surface accompanying gas evolution. High temperature $\left(\sim 10^{3} \mathrm{~K}\right.$ to $\left.10^{4} \mathrm{~K}\right)$ and pressure $\left(\sim 10^{2} \mathrm{MPa}\right)$ at micro discharge sites allow the formation of ceramic coatings composed not only of substrate oxides but also of more complex compounds, which involve species present in the electrolyte. For this reason, MAO coatings have excellent bonding strength with the substrate, good electrical and thermal properties, high micro hardness, high wear and corrosion resistance, etc. [5-7].

The corrosion resistance of MAO coatings is mainly determined by the electrolytes used in the MAO process and herein additives act as an important role to modify microstructure and corrosion resistance of the coating [7-10]. In particular, the addition of organic additives to the electrolyte is effective to decrease the size of microdefects and to improve the corrosion resistance of MAO coatings, due to a high surface activity at the solid-liquid interface [20]. However, the porous structure of ceramic coatings produced on $\mathrm{Mg}$ alloys by MAO process acts as a transportation channel for the corrosive medium that reaches the magnesium substrate [10-12]. Therefore, surface treatment methods using MAO process followed by post treatment have been proposed to further improve the corrosion resistance of Mg alloys [13-16]. 


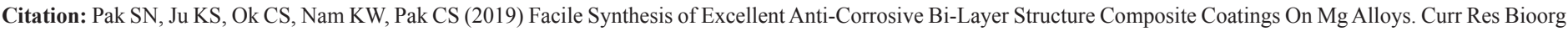
Org Chem 3: 121. DOI: 10.29011/2639-4685.100021

As an environmentally friendly surface modifier, phytic acid and silane are widely used to form an organic protective layer on the metal surface due to their high reaction activity [17-19]. Phytic acid $\left(\mathrm{C}_{6} \mathrm{H}_{18} \mathrm{O}_{24} \mathrm{P}_{6}\right)$, which is an environmental-friendly and naturally occurring acid in vegetables, fruits, and oil seeds, consists of 24 oxygen atoms, 12 hydroxyl groups and 6 phosphate carboxyl groups. As an organic macromolecule compound, phytic acid can easily form a protective film by adsorption on the surfaces of many metals, due to its powerful capability of chelating with metal ions such as $\mathrm{Cu}^{2+}, \mathrm{Fe}^{2+}, \mathrm{Fe}^{3+}, \mathrm{Zn}^{2+}, \mathrm{Ca}^{2+}$, and $\mathrm{Mg}^{2+}$ ions $[19,23,24]$. The general formula of silanes can be written as $\mathrm{X}_{3} \mathrm{Si}\left(\mathrm{CH}_{2}\right)_{n} \mathrm{Y}$. In the formula, Y stands for organofunctional groups (such as amino, vinyl, hydroxyl and glycidyl) which can react with polymers, and $\mathrm{X}$ is a hydrolysable alkoxy group [25]. Generally, the hydrolysis of alkoxy groups in silane solution produces the silanol group ( $\mathrm{Si}$ $\mathrm{OH})$, which can be coupled with hydroxylated $\mathrm{Mg}$ alloy surfaces $(\mathrm{Mg}-\mathrm{OH})$, via the formation of $\mathrm{Si}-\mathrm{O}-\mathrm{Mg}$ bonds [17]. The Si-O-Mg bonds cause the silane to act as an effective barrier to hinder the penetration of corrosive solution while the remaining silanol groups condense into Si-O-Si bonds originating highly cross-linked threedimensional network siloxane chains $[17,26]$. From this view, the addition of silane is preferable to improve the microstructure of the MAO coating during MAO process. Moreover, taking account of high reaction activity of phytic acid, the MAO coating post-treated by a phytic acid/silane hybrid is preferable to further improve the corrosion resistance of $\mathrm{Mg}$ alloys.

At present, the effects of various organic additives on MAO coatings have been investigated [20-23], but studies on the addition of silane as an additive in silicate electrolyte system have rare evidence. Moreover, there have been also little studies on the phytic acid/silane -based post treatment of the MAO coating.

In this paper, we have prepared excellent anti-corrosive bi-layer structure composite coatings by first MAO treating magnesium substrate in the silicate-based electrolyte containing silane as an organic additive and then modifying the MAO coating with phytic acid/silane hybrid. The corrosion resistance of the asfabricated composite coatings was also investigated (Table 1).

\section{Experiment}

\section{Preparation of MAO coatings}

AZ31B Mg alloy was used as the substrate and the chemical

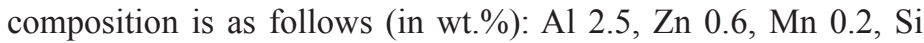
$0.08, \mathrm{Ca} 0.04, \mathrm{Mg}$ balance. All the samples were cut to a $25 \mathrm{~mm}$ $\times 20 \mathrm{~mm} \times 2 \mathrm{~mm}$ in size and were polished from 800 to 2000 grit $\mathrm{SiC}$ paper. Magnesium substrates were used as the anode and the stainless steel cell was used as the cathode. The temperature of the cell was controlled below $30{ }^{\circ} \mathrm{C}$ by stirring and cooling water flow. 3-aminopropyltrimethoxysilane (APTMS) was selected as an organic additive and added to the silicate-based electrolyte.
The whole MAO process was carried out under the electrolyte composition and electrical parameters shown in Table 1. After MAO treatment, the coated samples were rinsed with distilled water and dried in cold air.

\begin{tabular}{|c|c|}
\hline Electrolyte composition & $\begin{array}{c}10 \mathrm{~g} / \mathrm{L} \mathrm{Na} \mathrm{SiO}_{3}+3 \mathrm{~g} / \mathrm{L} \\
\mathrm{NaOH}+1 \mathrm{~g} / \mathrm{L} \mathrm{NaF} \\
+0.01 \sim 0.06 \mathrm{~mol} / \mathrm{L} \mathrm{C}_{6} \mathrm{H}_{17} \mathrm{NO}_{3} \mathrm{Si}\end{array}$ \\
\hline Current density $\left(\mathrm{A} / \mathrm{dm}^{2}\right)$ & 5 \\
\hline Frequency $(\mathrm{Hz})$ & 500 \\
\hline Duty ratio $(\%)$ & 20 \\
\hline Coating period (min) & 5 \\
\hline
\end{tabular}

Table 1: Electrolyte composition and electrical parameters.

\section{Modification of MAO coating}

The preparation process of phytic acid/silane hybrid for the post treatment of MAO coating is as following. First, $10 \mathrm{~mL}$ of APTMS ethanol solution $(0.006 \mathrm{~mol}$ L- 1$)$ was drop by drop added to $50 \mathrm{~mL}$ of PA solution $(0.012 \mathrm{~mol} \mathrm{~L}-1)$ under vigorous stirring at $25{ }^{\circ} \mathrm{C}$ temperature for $15 \mathrm{~min}$. Next, the reaction solution was kept under $75{ }^{\circ} \mathrm{C}$ for $3 \mathrm{~h}$ to complete the condensation reaction. The cleaned MAO-coated samples were immersed into the phytic acid/ silane hybrid solution at room temperature for 2 hours. After that, the samples were washed with deionized water and were dried in warm air.

\section{Testing methods}

The surface morphology and chemical composition of the MAO coatings were performed with Scanning Electron Microscopy (SEM; Quanta 200FEG) with Energy Dispersive Analysis of X-rays (EDX). The surface chemical compositions were determined with X-Ray Photoelectron Spectroscopy (XPS) (PHI 5700 ESCA System) with a monochromatic Al Ka source $(1486.6 \mathrm{eV})$. The thickness of the MAO coatings was measured using CTG-10 coating thickness gauge. In order to evaluate the corrosion resistance of all the samples, electrochemical experiments were conducted using CHI660 electrochemical analyzer (Shanghai, China) in a three-electrode cell containing $3.5 \mathrm{wt} \% \% \mathrm{NaCl}$ solution. (Pt plate was used as a counter electrode, Saturated Calomel Electrode (SCE) was used as a reference electrode and sample was used as a working electrode with reaction area of $1 \mathrm{~cm}^{2}$.) Tafel polarization curves were scanned at a rate of $1 \mathrm{mV} \mathrm{s}^{-1}$.

\section{Results and discussion}

\section{Voltage-time curves and thickness}

Figure 1 shows the voltage-time curves and thickness of the MAO coatings prepared in the electrolytes with different APTMS concentration. As shown in Figure 1a, the voltage increased rapidly in the first step (about $10 \mathrm{~s}$ ). During this step, there were 
no sparks and only some tiny oxygen bubbles could be observed on the surface of the sample, which indicates that the substrate begins to dissolve and a thin passive film is formed on the surface of AZ31B Mg alloy. In the second step (about $10 \mathrm{~s}$ to $180 \mathrm{~s}$ ), the rate of voltage increase was lower than in the first step and many tiny micro-arcs appeared along with oxygen evolution could be observed on the sample surface. The voltage at which micro-arcs occur is from $241 \mathrm{~V}$ to $258 \mathrm{~V}$, which increases with the increase of the APTMS concentration. In the third step (more than about $180 \mathrm{~s}$ ), the voltage increases slowly and then reach a stable value.
During the third step, the micro-arcs become larger and the sound changes to shrill. The sound in the electrolyte containing APTMS $(0.02 \sim 0.03 \mathrm{~mol} / \mathrm{L})$ was not so shrill compared with that in the base electrolyte and was relatively stable in the period of the third step. This means that the addition of APTMS could suppress large micro-arcs and give rise to maintaining the stability of the MAO process. The anode voltage gradually increased as the APTMS concentration increased, and the final voltages of MAO were $452 \mathrm{~V}$ $(0 \mathrm{~mol} / \mathrm{L}), 457 \mathrm{~V}(0.01 \mathrm{~mol} / \mathrm{L}), 462 \mathrm{~V}(0.02 \mathrm{~mol} / \mathrm{L}), 464 \mathrm{~V}(0.03$ $\mathrm{mol} / \mathrm{L}), 468 \mathrm{~V}(0.04 \mathrm{~mol} / \mathrm{L})$ and $477 \mathrm{~V}(0.06 \mathrm{~mol} / \mathrm{L})$, respectively.
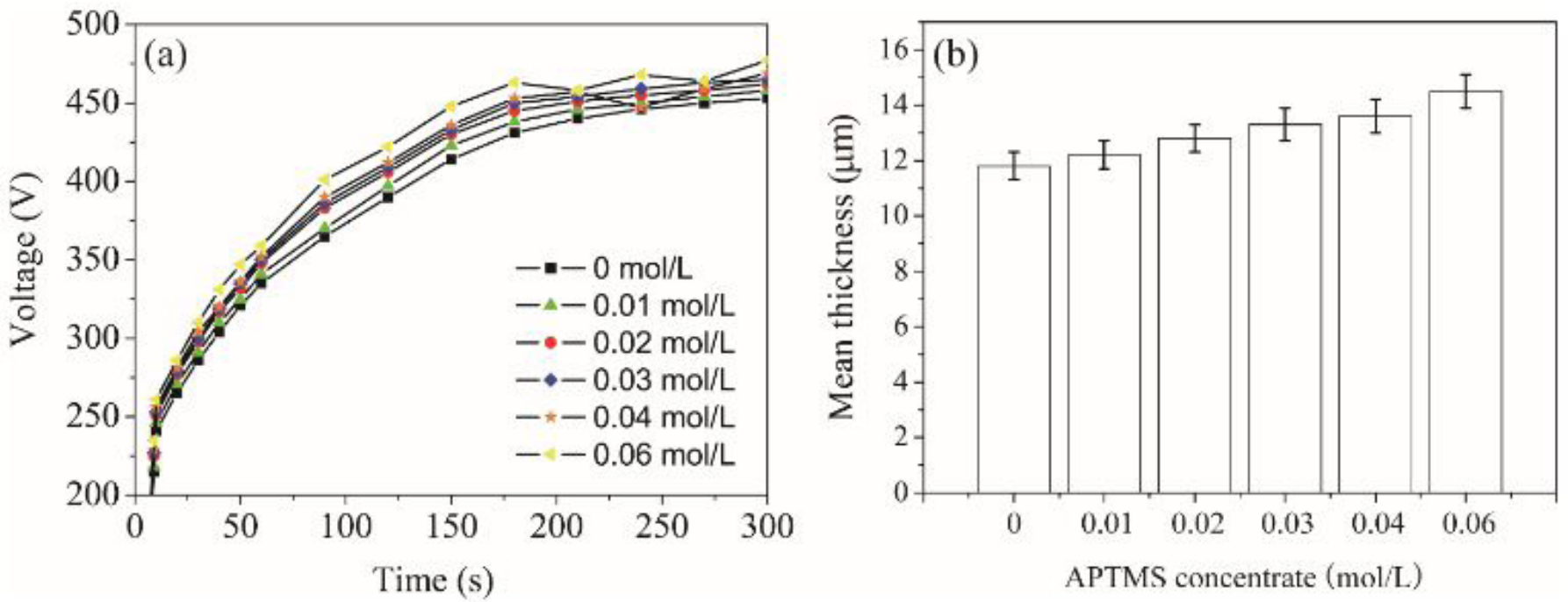

Figure 1: Voltage-time curves and thickness of the MAO coatings prepared in the electrolytes with different APTMS concentration: (a) voltage-time curves, and (b) mean thickness of the MAO coatings.

As the APTMS concentration increases, the conductivity of the electrolyte decreases while the resistance of the solution increases. Moreover, the resistance of the coating also increases due to adsorption of more organic additive molecules, which results in the increase of the anode voltage. Especially, in the third step, the anode voltage decreased and then increased again when the APTMS concentration was $0.04 \mathrm{~mol} / \mathrm{L}$ and $0.06 \mathrm{~mol} / \mathrm{L}$. The anode voltage increases with the increase of the APTMS concentration, which results in the severe damage of the coating due to the strong breakdown and discharge at the local position of MAO coating. This leads to the decrease of the anode voltage due to the decrease of the coating resistance and after a while, the anode voltage increases slowly as a new oxide film is formed. This phenomenon is disadvantageous to the corrosion resistance of the coating because it produces large micro-defects on the surface of the MAO coating.

From Figure 1b, it can be seen that the thickness is increased when adding APTMS. The average thickness increased with the increase of the APTMS concentration, and the average thicknesses of MAO coatings were $11.8 \pm 0.5 \mu \mathrm{m}(0 \mathrm{~mol} / \mathrm{L}), 12.2 \pm 0.5 \mu \mathrm{m}$ $(0.01 \mathrm{~mol} / \mathrm{L}), 12.8 \pm 0.5 \mu \mathrm{m}(0.02 \mathrm{~mol} / \mathrm{L}), 13.3 \pm 0.6 \mu \mathrm{m}(0.03$ $\mathrm{mol} / \mathrm{L}), 13.6 \pm 0.6 \mu \mathrm{m}(0.04 \mathrm{~mol} / \mathrm{L})$ and $14.5 \pm 0.6 \mu \mathrm{m}(0.06$ $\mathrm{mol} / \mathrm{L}$ ), respectively. The above results indicate that the addition of APTMS promotes the growth rate of the MAO coating under the same current density condition.

\section{Surface morphologies and composition}

Figure 2 shows the surface morphologies of the MAO coatings prepared in the electrolytes with different APTMS concentration. The pore sizes in all coatings are not even and the coatings all reveal several large micro-pores interspersed among a number of small micro-pores as well as some micro-cracks. Compared with the MAO coating prepared in the base electrolyte, the MAO coating prepared in the electrolyte with APTMS reveals the less pores and micro-cracks. When the APTMS concentration is $0.02 \mathrm{~mol} / \mathrm{L}$, the MAO coating reveals the relatively small pore 
Citation: Pak SN, Ju KS, Ok CS, Nam KW, Pak CS (2019) Facile Synthesis of Excellent Anti-Corrosive Bi-Layer Structure Composite Coatings On Mg Alloys. Curr Res Bioorg Org Chem 3: 121. DOI: 10.29011/2639-4685.100021

size $(0.5 \sim 4.5 \mu \mathrm{m})$ and the least micro-cracks. The larger pores began to appear when the APTMS concentration was $0.03 \mathrm{~mol} / \mathrm{L}$ and the relatively large pores $(10 \sim 20 \mu \mathrm{m})$ were formed when the APTMS concentration was $0.04 \sim 0.06 \mathrm{~mol} / \mathrm{L}$.

The different surface morphologies of the all coatings may be attributed to the different discharge characteristics during the MAO process. APTMS molecules are hydrolyzed into the silanol groups (amino propyl trihydroxy silane) in the electrolyte (reaction (1)).


Figure 2: Surface morphologies of the MAO coatings prepared in the electrolytes with different APTMS concentration: (a) 0 mol/L, (b) $0.01 \mathrm{~mol} / \mathrm{L}$, (c) $0.02 \mathrm{~mol} / \mathrm{L}$, (d) $0.03 \mathrm{~mol} / \mathrm{L}$, (e) $0.04 \mathrm{~mol} / \mathrm{L}$ and (f) $0.06 \mathrm{~mol} / \mathrm{L}$.

These hydroxyl groups of amino propyl trihydroxy silane could be adsorbed on the $\mathrm{Mg}$ surface by hydrogen bond, preventing water molecules from contacting with the Mg surface. Therefore, the anode voltage increased and the discharge centers were divided into smaller active sites to avoid the strong discharges. This leads to smaller discharge centers and less micro-cracks than in the base electrolyte.
$\mathrm{NH}_{2}\left(\mathrm{CH}_{2}\right)_{3} \mathrm{Si}\left(\mathrm{OCH}_{3}\right)_{3}+3 \mathrm{H}_{2} \mathrm{O} \rightarrow \mathrm{NH}_{2}\left(\mathrm{CH}_{2}\right)_{3} \mathrm{Si}(\mathrm{OH})_{3}+3 \mathrm{CH}_{3} \mathrm{OH}$

As the APTMS concentration increases, the anode voltage increases, which continuously induces strong discharge centers and produces large micro-pores as the result of connecting the surrounding micro-pores. The relatively large micro-pores were formed when the APTMS concentration was $0.04 \sim 0.06 \mathrm{~mol} / \mathrm{L}$, 


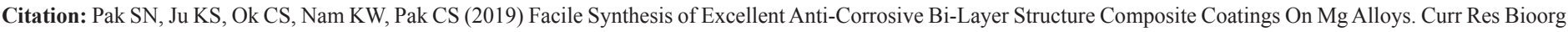
Org Chem 3: 121. DOI: 10.29011/2639-4685.100021

which is, as illustrated in voltage-time curves of Figure 1a, attributed to the strong breakdown and discharge induced by high anode voltage at local positions of the MAO coating.

Figure 3 shows the surface morphologies of the MAO coating prepared in the base electrolyte (B-coat), and the MAO coating prepared in the electrolyte with APTMS (A-coat, APTMS concentrate: $0.02 \mathrm{~mol} / \mathrm{L}$ ) and phytic acid/silane hybrid modified MAO coating(A/hybrid-coat), and EDX result for the surface morphology of A/hybrid-coat. As shown in Figure 3a and 3b, B-coat has the extended micro-cracks and its pore size ranges from 0.5 to $6.0 \mu \mathrm{m}$. After the addition of APTMS, the pore size of A-coat reveals the smaller pore size $(0.5-4.5 \mu \mathrm{m})$ and the less micro-cracks. On the other hand, the pores in A/hybrid-coat are covered with new materials of network morphology in nanoscale (Figure 3c). This indicates that the surface structure of the MAO coating was changed by phytic acid/silane hybrid modification. As seen from EDX analysis of Figure 3d, the surface of A/hybrid-coat is mainly containing Mg, $\mathrm{O}, \mathrm{C}$, $\mathrm{Si}, \mathrm{P}$ and $\mathrm{N}$, among which $\mathrm{P}$ was derived from phytic acid and $\mathrm{N}$ came from APTMS.
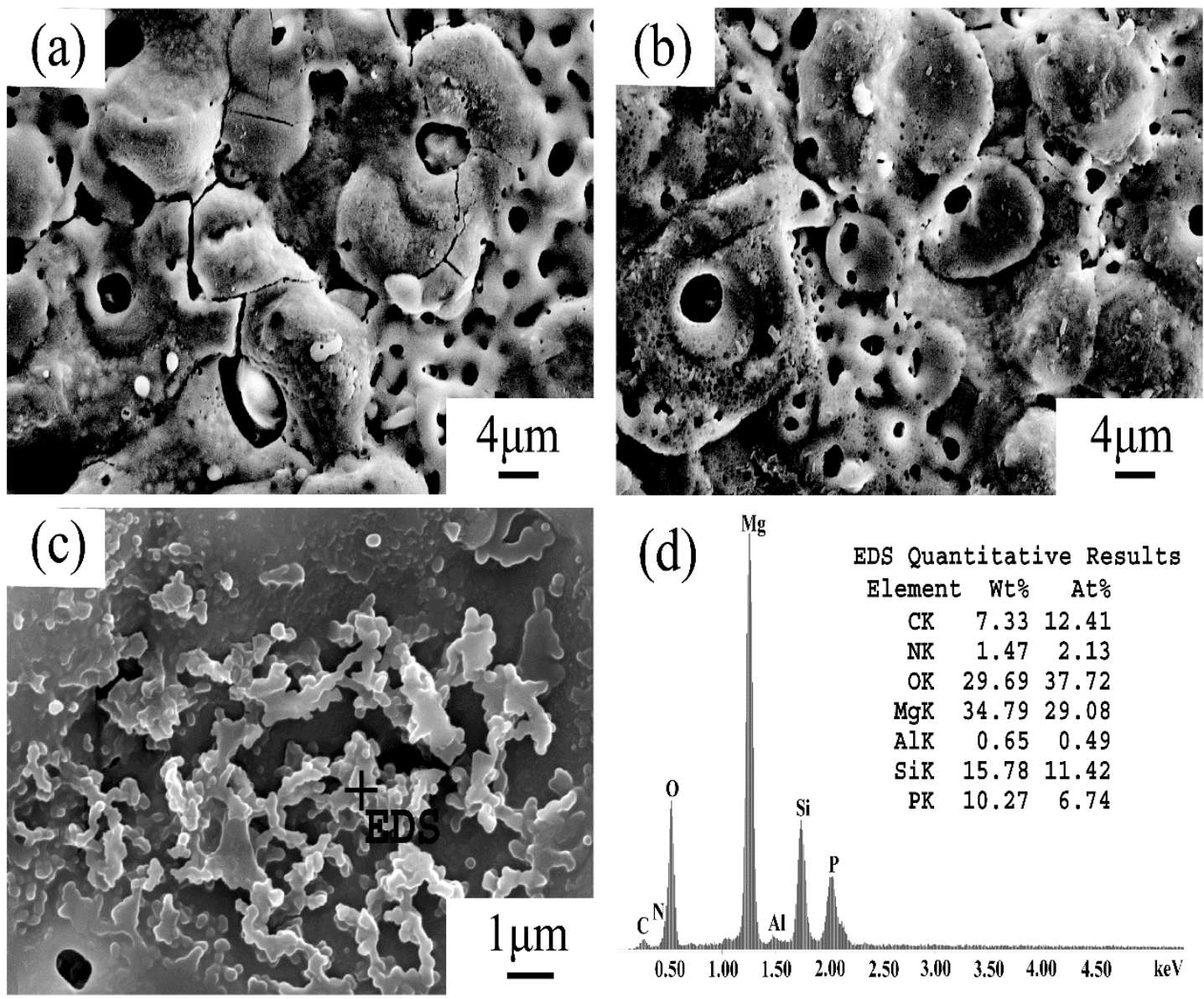

Figure 3: Surface morphologies of the MAO coatings and composite coatings: (a) B-coat, (b) A-coat, (c) A/hybrid-coat, (d) EDX result for the surface morphology of A/hybrid-coat.

Figure 4 shows XPS survey spectra for the surface of A-coat and A/hybrid-coat. Based on XPS survey spectrum, A/hybrid-coat gives more prominent oxygen and carbon peaks as well as peaks related to the elements of $\mathrm{P}$ and $\mathrm{N}$ compared with A-coat. This is consistent with the EDX result and it is a good evidence that the phytic acid/silane hybrid was coupled to A-coat. 


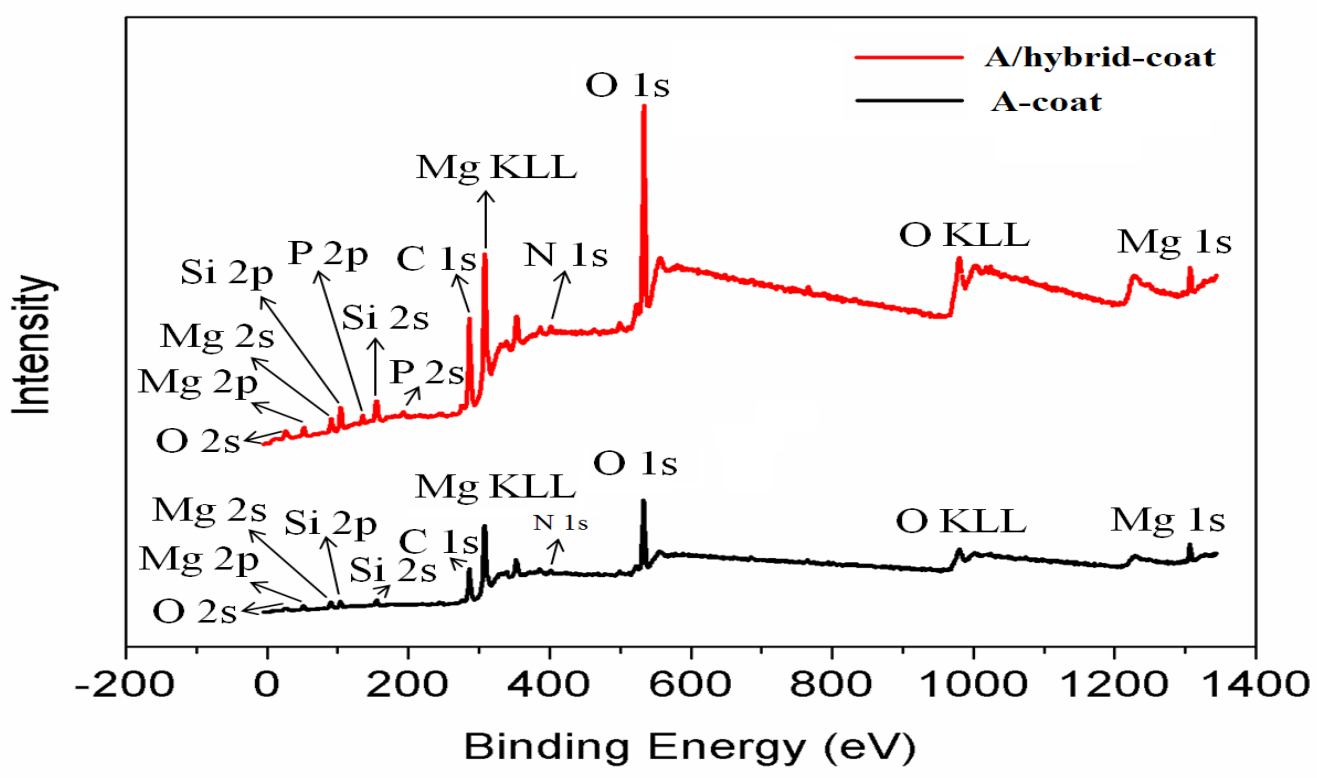

Figure 4: XPS survey spectra of A-coat and A/hybrid-coat.

The phytic acid/silane hybrid is a condensation product between the silanol groups and phytic acid. Silanol groups can provide $\mathrm{Si}-\mathrm{O}$ bonds or provide $\mathrm{Si}-\mathrm{O}-\mathrm{Si}$ bonds which is produced by condensation reactions between silanols, and hence phytic acid/ silane hybrid of network structure in nanoscale can be formed via P-O-Si bonds [24]. Phytic acid/silane hybrid is a kind of organic acid containing a lot of PA monomers and it exhibits very strong complexation ability with $\mathrm{Mg}$ ions. Therefore, phytic acid radicals of phytic acid/silane hybrid could react with magnesium oxide of the MAO coating and reinforced networks with high cross-link density in nanoscale are formed on the MAO coating.

\section{Corrosion performance}

Figure 5 shows the potentiodynamic polarization curves of the MAO coatings prepared in the electrolytes with different APTMS concentration. The relevant corrosion potential $\left(E_{c o r r}\right)$ and corrosion current $\operatorname{density}\left(i_{\text {corr }}\right)$ are given in Table 2 . As the APTMS concentration increased, the corrosion current density of the MAO coating initially decreased and then increased again. When the APTMS concentration was $0.02 \mathrm{~mol} / \mathrm{L}$, the lowest corrosion current density and the highest corrosion potential were observed, which is assigned to the restriction of the penetration of the corrosive $\mathrm{Cl}^{-}$ions due to the fewest micro-defects in the MAO coating. The corrosion current density increased when the APTMS concentration was $0.04 \mathrm{~mol} / \mathrm{L} \sim 0.06 \mathrm{~mol} / \mathrm{L}$, which is associated with the penetration of the corrosive medium through the larger micro-pores produced by high anode voltage. But the corrosion current density in the APTMS concentration of $0.06 \mathrm{~mol} / \mathrm{L}$ is low due to the relatively large coating thickness.

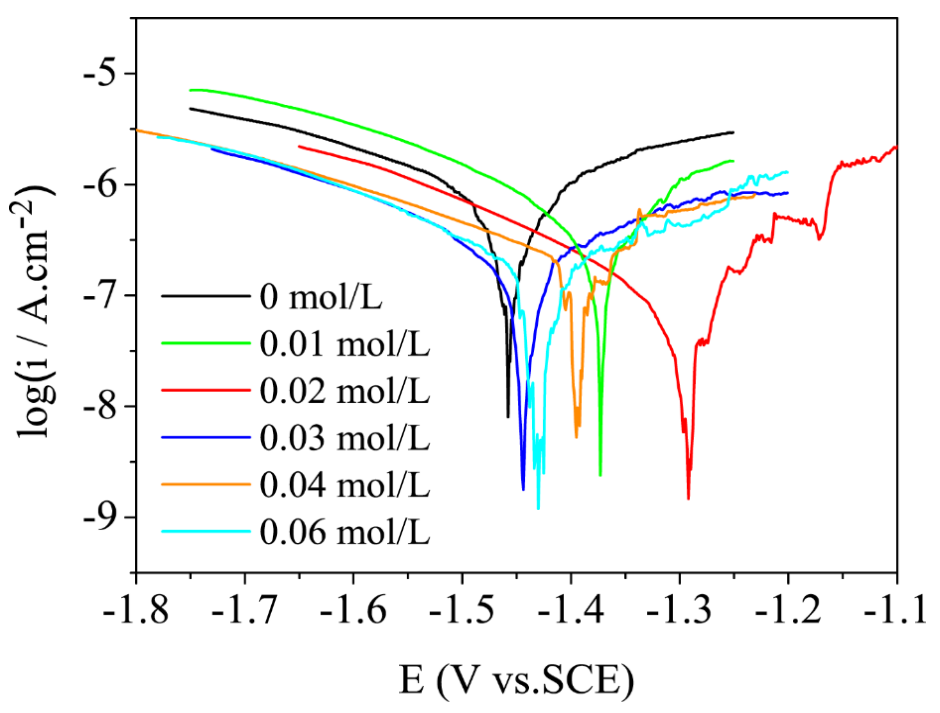

Figure 5: Potentiodynamic polarization curves of the MAO coatings prepared in the electrolytes with different APTMS concentration. 


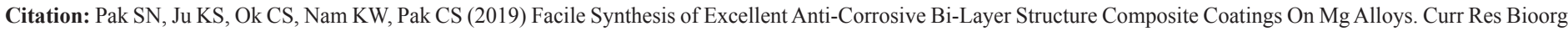
Org Chem 3: 121. DOI: 10.29011/2639-4685.100021

\begin{tabular}{|c|c|c|c|c|c|c|}
\hline Concentration $(\mathrm{mol} / \mathrm{L})$ & 0 & 0.01 & 0.02 & 0.03 & 0.04 & 0.06 \\
\hline$E_{\text {corr }}(\mathrm{V}$ vs.SCE $)$ & -1.457 & -1.373 & -1.291 & -1.445 & -1.392 \\
\hline$i_{\text {corr }}\left(\mathrm{A} / \mathrm{cm}^{2}\right)$ & $8.32 \times 10^{-7}$ & $6.04 \times 10^{-7}$ & $2.03 \times 10^{-7}$ & $4.21 \times 10^{-7}$ & $5.18 \times 10^{-7}$ & $3.94 \times 10^{-7}$ \\
\hline
\end{tabular}

Table 2: The results of potentiodynamic polarization curves from Figure 5.

Figure 6 shows the potentiodynamic polarization curves of the MAO coatings and composite coatings. (B/hybrid-coat denotes phytic acid/silane hybrid modified B-coat.) The relevant corrosion potential and corrosion current density are given in Table 3 . The corrosion current density of A-coat is lower than that of B-coat, which is, as shown in Figure $1 \mathrm{~b}$ and $3 \mathrm{~b}$, attributed to its less microdefects and the larger thickness. The corrosion current densities of the as-fabricated composite coatings (B/hybrid-coat and A/hybridcoat) represent the decrease of more than one order of magnitude compared with the MAO coatings. In particular, the corrosion current density of $\mathrm{A} /$ hybrid -coat is lower than that of $\mathrm{B} /$ hybridcoat.

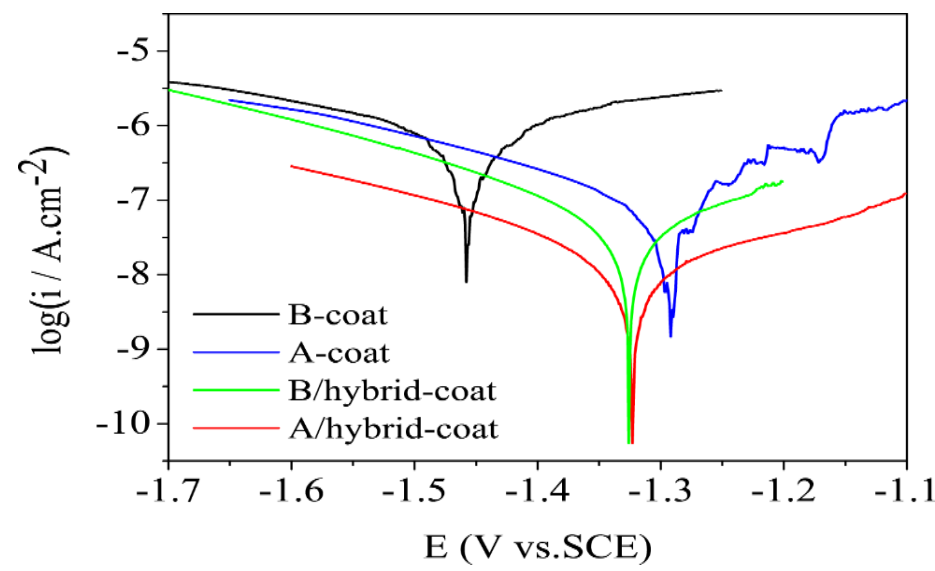

Figure 6: Potentiodynamic polarization curves of the MAO coatings and composite coatings.

\begin{tabular}{|c|c|c|c|c|}
\hline Coating & B-coat & A-coat & $\begin{array}{c}\text { B/hybrid- } \\
\text { coat }\end{array}$ & $\begin{array}{c}\text { A/hybrid- } \\
\text { coat }\end{array}$ \\
\hline $\begin{array}{c}E_{\text {corr }}(\mathrm{V} \\
\text { vs.SCE })\end{array}$ & -1.457 & -1.291 & -1.326 & -1.323 \\
\hline$i_{\text {corr }}\left(\mathrm{A} / \mathrm{cm}^{2}\right)$ & $8.32 \times 10^{-7}$ & $2.03 \times 10^{-7}$ & $4.46 \times 10^{-8}$ & $1.81 \times 10^{-8}$ \\
\hline
\end{tabular}

Table 3: The results of potentiodynamic polarization curves from Figure 6.

This means that the corrosion resistance of the MAO coating was improved by sealing effect of micro-defects due to the phytic acid/silane hybrid of network structure in nanoscale. In case of A/ hybrid -coat, the better anti-corrosive performance results from the joint effect of thickness and microstructure due to APTMS doping and phytic acid/silane hybrid modification.

\section{Conclusions}

The excellent anti-corrosive bi-layer structure composite coatings comprising of the APTMS doped MAO coating and phytic acid/silane hybrid were fabricated on AZ31B magnesium alloy. The addition of APTMS provides a better corrosion resistance to the MAO coating due to the smaller pore size, less micro-crack, and larger thickness. Moreover, phytic acid/silane hybrid modification effectively sealed the micro-defects of MAO coatings with precipitates of network structure in nanoscale. Therefore, the as-fabricated composite coatings effectively restrict the penetration of a corrosive medium into the $\mathrm{Mg}$ alloy substrate, representing an excellent corrosion barrier effect.

\section{References}

1. Guo H, An M, Xu S, Huo H (2006) Micro arc oxidation of corrosion resistant ceramic coating on a magnesium alloy. Mater Lett 60: 15381541.

2. Wang Z, Li Q, She Z, Chen F, L. Li, et al. (2013) Facile and fast fabrication of super hydrophobic surface on magnesium alloy. Appl Surf Sci 271: 182-192.

3. Chen Y, Qian H, Wang X, Liu P, Yan G, et al. (2015) To improve corrosion resistance and hemocompatibility of magnesium alloy via cathodic plasma electrolytic deposition combined with surface thiol-ene photo polymerization. Mater Lett 158: 178-181.

4. Zhuang JJ, Song RG, Xiang N, Xiong Y, Hu Q (2017) Effect of current density on microstructure and properties of PEO ceramic coatings on magnesium alloy. Surf Eng 33: 744-752.

5. Stojadinović S, Vasilić R, Perić M (2014) Investigation of plasma electrolytic oxidation on valve metals by means of molecular spectroscopy-a review. RSC Adv 4: 25759-25789.

6. Li QB, Liu CC, Yang WB, Liang J (2017) Growth mechanism and adhesion of PEO coatings on 2024Al alloy. Surf Eng 33: 760-766.

7. Soliman H, Hamdy AS (2017) Effect of fluoride ions modifier and ceramic $\mathrm{Al}_{2} \mathrm{O}_{3}$ particles additives on plasma electrolytic oxidation of AZ31. Surf Eng 33: 767-772.

8. Shi L, Xu Y, Li K, Yao Z, Wu S (2010) Effect of additives on structure and corrosion resistance of ceramic coatings on Mg-Li alloy by microarc oxidation. Curr Appl Phys 10: 719-723.

9. Ghasemi A, Scharnagl N, Blawert C, Dietzel W, Kainer KU (2010) Influence of electrolyte constituents on corrosion behaviour of PEO coatings on magnesium alloys. Surf Eng 26: 321-327.

10. Wang Y, Yu H, Chen C, Zhao Z (2015) Review of the biocompatibility of micro-arc oxidation coated titanium alloys. Mater Des 85: 640-652. 


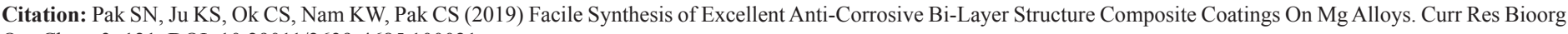
Org Chem 3: 121. DOI: 10.29011/2639-4685.100021

11. Wang YQ, Deng YZ, Shao YW, Wang FH (2014) New sealing treatment of microarc oxidation coating. Surf Eng 30: 31-35.

12. Sankara Narayanan TSN, Park IS, Lee MH (2014) Strategies to improve the corrosion resistance of microarc oxidation (MAO) coated magnesium alloys for degradable implants: prospects and challenges. Prog Mater Sci 60: 1-71.

13. Chen MA, Ou YC, Yu CY, Xiao C, Liu SY (2016) Corrosion performance of epoxy/BTESPT/MAO coating on AZ31 alloy. Surf Eng 32: 38-46.

14. Cui XJ, Lin XZ, Liu CH, Yang RS, Zheng XW, et al. (2015) Fabrication and corrosion resistance of a hydrophobic micro-arc oxidation coating on AZ31 Mg alloy. Corros Sci 90: 402-412.

15. Ivanou DK, Starykevich M, Lisenkov AD, Zheludkevich ML, Xue HB, et al. (2013) Ferreira, Plasma anodized ZE41 magnesium alloy sealed with hybrid epoxy silane coating. Corros Sci 73: 300-308.

16. Lin X, Tan L, Wan P, Yu X, Yang K, et al. (2013) Characterization of micro-arc oxidation coating post-treated by hydrofluoric acid on biodegradable ZK60 magnesium alloy. Surf Coat Technol 232: 899-905.

17. Tong LB, Zhang JB, Xu C, Wang X, Song SY, et al. (2016) Enhanced corrosion and wear resistances by graphene oxide coating on the surface of Mg-Zn-Ca alloy. Carbon 109: 340-351.

18. Ezhil Vizhi M, Vanithakumari SC, George RP, Vasantha S, Kamachi MU (2016) Super hydrophobic coating on modified $9 \mathrm{Cr}-1$ Mo ferritic steel using perfluoro octyl triethoxy silane. Surf Eng 32: 139-146.

19. Pan F, Yang X, Zhang D (2009) Chemical nature of phytic acid conversion coating on AZ61 magnesium alloy. Appl Surf Sci 255: 83638371.
20. Wu D, Liu X, Lu K, Zhang Y, Wang $\mathrm{H}$ (2009) Influence of $\mathrm{C}_{3} \mathrm{H}_{8} \mathrm{O}_{3}$ in the electrolyte on characteristics and corrosion resistance of the microarc oxidation coatings formed on AZ91D magnesium alloy surface. Appl Surf Sci 255: 7115-7120.

21. Cai QZ, Wang LS, Wei BK, Liu QX (2006) Electrochemical performance of microarc oxidation films formed on AZ91D magnesium alloy in silicate and phosphate electrolytes. Surf Coat Technol 200: 37273733 .

22. Bai A, Chen ZJ (2009) Effect of electrolyte additives on anti-corrosion ability of micro-arc oxide coatings formed on magnesium alloy AZ91D. Surf Coat Technol 203: 1956-1963.

23. Zhang RF, Zhang SF, Duo SW (2009) Influence of phytic acid concentration on coating properties obtained by MAO treatment on magnesium alloys. Appl Surf Sci 255: 7893-7897.

24. Gao X, Lu K, Xu L, Xu H, Lu H, et al. (2016) Excellent anti-corrosive pretreatment layer on iron substrate based on three-dimensional porous phytic acid/silane hybrid†. Nanoscale 8: 1555-1564.

25. Yue YY, Liu ZX, Wan TT, Wang PC (2013) Effect of phosphate-silane pretreatment on the corrosion resistance and adhesive-bonded performance of the AZ31 magnesium alloys. Prog Org Coat 76: 835-843.

26. Chakraborty BP, Singh RRK (2011) Electrochemical impedance spectroscopic investigation of the role of alkaline pre-treatment in corrosion resistance of a silane coating on magnesium alloy. ZE41 Electrochim Acta 56: 3790-3798. 